\title{
The Necessity of College Teachers Managing towards "Ecology"*
}

\author{
Xiaoqiong Zhou \\ Personnel Department \\ China West Normal University \\ Nanchong, China 637009
}

\begin{abstract}
Traditional rigid "scientific management" is not conducive to arouse teachers' enthusiasm and soft "humanistic management" ignores the content and system of the factors in the management. In contrast, the "ecological faculty management" is soft and supple which overcomes the defects of the traditional teaching management by using the "system", "whole" and "mutual benefit" concept. It opens up a new model of teacher management.
\end{abstract}

\section{Keywords-scientific management;}

human-based management; ecological teacher management

\section{INTRODUCTION}

The management of teachers in colleges and universities in China mainly goes through two stages: "scientific management" with efficiency as the goal and "human-based management" with the goal of teacher development. The purpose of "scientific management" is to promote the efficiency of teacher management. Human-based management aims at overcoming the problem of teachers' dissatisfaction with teacher standardization and institutional vassal in scientific management and thereby dampening the enthusiasm of teachers. However, the limitations of these two kinds of management are also obvious. The former attaches great importance to the pursuit of "quantity" and lacks humanistic concern, while the latter neglects other factors besides "people" in management activities. Based on this, it is necessary to overcome the "dualistic" thinking in management thinking and to promote the management toward communion of the "quality" and "quantity". Ecological Management From the ecological point of view, the whole management system is regarded as an ecosystem composed of ecological subjects (including teachers and managers) and management environment. It is believed that optimizing the various ecological elements and ecological environment can promote ecological system of teachers' management safe, stable, coordinated and sustainable development. It not only helps to avoid the shortcomings of the traditional management methods, but also helps to develop its merits. It is a new management method that can be surpassed in inheritance. It is a new model to promote teacher management to meet the demands of "quality" and "quantity".

*The research is financed by Education Department of Sichuan Province Project (Project No. 16SB0104)

\section{THE CHARACTERISTICS, ADVANTAGES AND DISADVANTAGES OF SCIENTIFIC MANAGEMENT}

Scientific management theory began in the late 19th century from experiments of Taylor, "father of Science and Management" on "production standardization" and other aspects of scientific management experiments and research. He focused on how to improve production efficiency through standardization of production techniques and production tools in workshop management. He proposed "five principles" for improving production [1]: (1) work quota. The daily work of workers should have a "reasonable daily workload", that is, work quota. (2) Standardization. Let workers use standard practices in their work and use standardized tools and machine materials to increase productivity. (3) Ability and work to adapt. Choose the most capable workers who are best suited to do something to increase productivity. (4) Different piece-rate payment according to the completion of the work quota implementation rewards and punishments. (5) The planning function is separated from the executive function. Scientific management also bases on the classical management schools such as Henri Fayol [2 and the French administration theory which emphasizes the management through the strict management system and laws and regulations within the organization, finally achieving the ideal management objective.

The purpose of the Scientific Management of Enterprises and Factories being incorporated in the teacher management of colleges and universities is to rely on scientific management principles, systems, methods and processes to plan, organize, allocate and control teachers and eventually achieve the management goals effectively and efficiently. Its core content is to assess the workload of individual staff and work performance, co-management and management departments to mobilize the enthusiasm of staff. The main characteristics of scientific management of teachers in colleges and universities are reflected in several aspects: First, starting from pursuing efficiency, carrying out targeted management and successfully achieving the expected goals; secondly, designing based on scientific rules and regulations, work flow and organizational structure to urge faculty to complete the required indicators. Third, aiming at the pursuit of the quantitative management based on the quantitative assessment of staff performance. For example, the promotion 
of titles requires teachers of publishing a number of papers applying for a certain level of research projects and so on. Fourthly, the relationship between managers and faculty is "command-executive". Managers are the system makers, executors and interpreters, lying in the absolute authority of the position; faculty and staff subject to the well-designed organizational framework, its thinking and personality are under control, passively accepted. If the entire management process metaphor for a game, then the manager is the game organizer, executor and referee and the staff is the athlete. Whether the true level of athletes can be reflected, to a large extent depends on the scientific nature of the organization's procedures, the game content and competition rules and other external factors.

The advantages and disadvantages of scientific management are obvious. The advantages are: (1) quantitative management is easy to operate. Managers and being managed have a clear goal to act in accordance with the rules to ensure the smooth implementation of the work; (2) rule-based and evidence-based is easy to avoid the management process being disturbed by the subjective consciousness. (3) Clear objectives and specific tasks can reduce the distracting of redundant matters in the management process and maximize the management efficiency. (4) By linear management, responsibility, rewards and punishments are clear. The defects lie in: (1) the onesided pursuit of the goal may neglect the "qualitative" factors because of focusing on "quantity". (2) Under the linear management mode from the manager to the teacher, it's hardly stimulates the teacher's initiative because the manager regards the teacher as the tool which accomplishes each task index and does not form the effective interaction with the teacher. (3) ignoring the teacher's emotion, the lack of human nature, ethics and the care, it is not conducive to the use of emotional, value goals and behavioral standards and other flexible factors to achieve incentives for faculty and staff is not conducive to mobilize the enthusiasm of the internal factors to participate in the goal Construction. (4) Using rigid target management, flexibility is not enough to stimulate innovation.

\section{FEATURES, STRENGTHS AND WEAKNESSES OF BEHAVIORAL MANAGEMENT}

The way of scientific management alienates the teacher as the vassal of the standard and the system is not conducive to the teacher's true enthusiasm. For the management of university teachers, because faculty members are engaged in complex mental work and their labor outcomes are special, even though the smooth completion of the goal can be ensured, it cannot guarantee the quality of completing the target with the rude, mechanical, standardized, supervising and highly controlled scientific management methods. Therefore, the requirement of "quality" of management effect impels teachers' management to focus on the psychological, behavioral and other factors of management goals, and realizes the transformation of management effectiveness from "quantity" to "quality". Because of the above characteristics concerning "people" in work, the management approach enterprise has entered the field of university faculty management.

Behavioral Science Theory studies originated from the Hawthorne experiment led by G.E. Mayo (1924-1932). The result of this experiment concludes that people play the dual roles of "economic man" and "social man"[3]. The effect of scientific management is reflected in the management of "economic man", but it is hard to work for man as a "social man". The hierarchy of needs of A.H. Maslow [4] and the two-factor theory of F. Herzberg [5] further illustrate the complexity of human nature. The former believes that people's needs are evolving at different levels in a step-bystep manner. When a certain level needs to be met and a higher-level need arises, the incentives needed by the original level will disappear. The latter believes that the factors that affect the performance of personnel behavior is divided into two kinds: "health factors" and "incentives". "Health care factors" refers to the factors that "being not dissatisfied when they are obtained but not obtained if they are not obtained". The effect of the former factor is quicker for mobilizing enthusiasm but less time-sensitive. The latter factor is less effective at mobilizing enthusiasm but has a long history of failure. Therefore, it is very important only through flexible management to mobilize staff approval of management and take the initiative to participate in management stimulate their true enthusiasm.

With these theories and practical achievements, in the critique of neglecting "human" factors in management, teacher management of colleges and universities go from scientific management to humanistic management. Whether can improve the quality of teaching staff and stimulate their intrinsic potential and enthusiasm become an important standards of measuring the level of management. This management also has very obvious characteristics:

First, it recognizes the value of every employee and it aiming at motivating all employees to achieve self-worth. Second, it pays attention to the diversity needs of faculty and staff and considers their needs both physically and mentally. Third, it adopts a flexible approach to promote the recognition of management staff and establish self-discipline and internal drive. Fourth, the manager's role shifts from "management" to "service", creating a relaxed atmosphere for management activities, increasing the sense of belonging and willingness to participate in management of faculty and staff, and thus exerting their potential on the part of workers with a sense of ownership. Human-based management shows superiority in many aspects: (1) by highlighting the status and role of faculty and staff in management activities can stimulate their active participation awareness. Thus, "team work" is conducive to innovation in management style. (2) Humane care for teaching staff and increasing emotional investment can reduce their resistance which is helpful for the promotion of management activities. (3) It can provide conditions for the realization of the personal value of faculty and staff and enhance their working enthusiasm. (4) The formation of the internal driving force will be transformed into a long-term incentive to provide long-term effective management and protection. However, its shortcomings are also obvious. For example, human nature is complex, if 
everyone should be encouraged to realize value, then: how do we coordinate the relationship between people? How do we grasp the role of objects and systems in the management of work? All the problems concerning these are difficult to be solved by humanistic management.

\section{TEACHERS' ECOLOGICAL MANAGEMENT}

These two kinds of teacher management above have advantages and disadvantages, and in essence, they are products of the dualistic opposition. This objectively calls for a new management approach that can evade both shortcomings and promote the merits, so as to get surpass. The ecological management of teachers emerges from time to time. Although as a new research field, it is difficult to define teachers' ecological management clearly, it is clear that it is both the embodiment of ecological management thought and the application of ecological management thought in teacher management.

Ecological management originated in the United States in the seventies of the last century and swept the field of management in the nineties. It is a combination of ecology and management and it is the concept of ecology used in management interdisciplinary practice which is designed to use ecological thinking to promote the transformation of management thinking. Some scholars define it as "using the systematic, comprehensive and organic ecological theories and thinking methods to study the entire management ecosystem and its laws, treating the entire management ecosystem as an 'organism', paying attention to the 'interactive' of this 'organism', and emphasizing on the use of ecological simulation method to establish the management of the ecological model "[6] Some scholars claim that "ecological management is a profound revolution in the management history, although it is not yet mature, but there is still some common understanding". These consensuses are obvious: First of all, it believes that management needs to uphold the principle of holism. Just as all the elements in an ecosystem are interdependent and they interact with each other, all the elements of a management system are also an organic whole that they interact with each other. Therefore, applying ecological holism to the field of organization and management field and using the ecological thinking paradigm to guide the organization and management concepts and changes in management behavior can ensure the management of a coordinated, stable and sustainable development. Second, it adheres to the principle of symbiotic coexistence and holds that all stakeholders should be involved in the formulation of management plans and to safeguard the rights and interests of all people in management activities so as to give the management body the inherent impetus for self-growth. Third, it respects differences and emphasizes the guarantee of harmony in management and the sustainability of development on the basis of respecting the inherent characteristics of development subjects and the particularities and inherent laws in specific management fields.

The so-called teacher's ecological management, from a literal point of view, is the management practice of applying the idea of ecological management in the field of teacher management and is an ecological management directed at a special group of teachers. The whole system of conventions in this model is regarded as an organic ecosystem composed of managers, teachers and the environment. In the system, the various elements interact and depend on each other to achieve dynamic balance in harmonious coexistence. As a new management model, teachers' ecological management has its own distinct features and advantages.

First, this management is consistent with the inherent characteristics of teacher development and organizational operations. College teacher groups are highly educated intellectuals with high professional titles, high quality and other characteristics. This group is more likely to flow, and to stabilize such a team must conduct scientific humanity management. Through the establishment of a harmonious management environment, teacher's ecological management not only allows teachers to play the role of administrator, but also enables teachers to take part in management with an open and democratic attitude. Through the sincere, equal and open dialogue between the subjects, they aim at realizing the relative unity of cognition and the consistency of the behaviors to the greatest extent, and being integrated into one organic community in order to fully realize the personal value of the subject.

Second, this management increases the sense of belonging and empowerment of teachers through "coexistence, mutualism and mutual benefit". Teachers' Ecological Management thinks that efficient management activities are the result of positive interaction between managers, teachers and the environment. Therefore, all elements of a management activity should cooperate with one another in the common vision of "working together" to achieve common benefits. The most important prerequisite for safeguarding the harmonious relations among the three is equality and opening up. For example, managers and teachers should establish an equal relationship and push forward the management activities in the consensus through continuous democratic dialogue, and through the collision of ideas, complete the exchange of information and the updating of ideas.

Third, this kind of management acknowledges the difference and it can maximize the motivation of the subjects. Teacher ecological management is a kind of appropriate management. Because each teacher's innate endowment, growth environment, cultural level, business ability, work attitude, personal expertise, hobbies, the level of development and so on are different, teacher ecological management recognizes these differences and based on them, it takes different ways and means on the evaluation criteria, incentives, training forms in order to achieve the use of people to avoid weaknesses and inspire their inner motivation by providing each with the opportunity to achieve personal value.

Fourth, this management adheres to the concept of holistic and systematic observation, which can achieve the coordinated and sustainable development of teachers and organizations. Teachers' ecological holism and the concept of the ecosystem embody firstly in paying attention to the 
beneficial combination of various relations in the system under the guidance of organic, whole, dynamic and harmony concepts avoiding short-sighted and temporarily local development to undermine the long-term overall development. Second, it also requires that management activities to be based on the inherent characteristics of the development of all things and it emphasizes the regularity of management and examine various management activities from the perspective of systematic development. In addition, it requires the long-term effects and healthy development of management activities and emphasizes on the balance among all the various elements in the management system. For example, while tap a teacher's potential as far as possible a teacher, his physical and mental health is also protected. Over-developed and over-expenditure of teachers mental and physical is not permitted and on the contrary, it is necessary to provide various conditions to support teachers with knowledge, ability, time, emotion and other comprehensive preparation for ensuring their sustainable development

\section{CONCLUSION}

The "scientific management" aiming at efficiency is a kind of "rigid" means, which is not conducive to mobilizing the enthusiasm of teachers. "Humanistic management"" is a kind of "flexible" means, ignoring the factors in the management of materials and systems. The overall ecological management which applies the concept of ecology in teacher management makes up for the shortcomings of those above two management ways. It is a management model of "rigid and soft", so it is very necessary to realize the transformation from traditional management to ecological management.

\section{REFERENCES}

[1] Frederick Taylor. The Principles of Scientific Management. New York and London: Harper \& brothers. 1911.

[2] Henri Fayol. Industrial and General Administration. London: Sir Isaac Pitman \& Sons. 1930.

[3] George Elton Mayo: The Human Problems of an Industrial Civilization, Routledge, reprint edition 2003.

[4] A. H. Maslow. A Theory of Human Motivation. Psychological Review. 1943.

[5] Herzberg. The Motivation to Work. New York: John Wiley and Sons. 1959.

[6] Chen Xiangyang. School's Recessive management. Nanning: Guangxi Education Press. 2006. 